Tropical Journal of Pharmaceutical Research March 2020; 19 (3): 571-575

ISSN: $1596-5996$ (print); 1596-9827 (electronic) (C) Pharmacotherapy Group, Faculty of Pharmacy, University of Benin, Benin City, 300001 Nigeria.

\title{
Effect of dexmedetomidine post-treatment on oxidative stress and apoptosis induced by myocardial ischemia- reperfusion injury in rats
}

\author{
Zhihai Geng ${ }^{1}$, Xuelian Zhu ${ }^{1}$, Xi Han $^{2}$, Xianfeng Xin ${ }^{1 *}$ \\ ${ }^{1}$ Department of Anesthesiology, First Affiliated Hospital of Jiamusi University, ${ }^{2}$ Department of Anatomy, School of Basic Medical \\ Sciences, Jiamusi University, Jiamusi, PR China
}

*For correspondence: Email: ct44cn@163.com

Sent for review: 18 December 2019

Revised accepted: 26 February 2020

\begin{abstract}
Purpose: To study the effect of dexmedetomidine on myocardial ischemia-reperfusion injury (MI/RI)induced imbalance on oxidant-prooxidant status and apoptotic changes in rats.

Methods: Ninety (90) male Wistar rats were randomly divided into three groups - sham, model and post-treatment. In model rats, the anterior descending branch of the left coronary artery was ligated for $25 \mathrm{~min}$, prior to their being subjected to reperfusion for $2 \mathrm{~h}$. Rats in the post-treatment group were subjected to ligation at the anterior descending branch of the left coronary artery for 25 min, but they were intravenously injected with dexmedetomidine at a dose of $10 \mu \mathrm{g} / \mathrm{kg}$ prior to reperfusion. There was no ligation in the sham group. Malondialdehyde (MDA), glutathione peroxidase (GSH-Px) and superoxide dismutase (SOD) were assayed. Lactate dehydrogenase $(L D H)$ and creatine kinase isoenzyme (CK-MB) levels were also evaluated. Apoptosis was measured with TdT-mediated dUTP nick end labeling (TUNEL) assay.

Results: Compared with the sham group, MDA level in the model group was significantly rose, while $S O D$ and GSH-Px activities were markedly decreased $(p<0.05)$. Moreover, there were higher LDH and $C K-M B$ activities in model rats than in the sham rats, but they were significantly lower in the posttreatment group than in the model group $(p<0.05)$. Apoptosis was higher in model rats than in sham operation rats, but was markedly decreased in post-treatment rats than in model rats $(p<0.05)$.

Conclusion: Post-treatment with dexmedetomidine exerts myocardial protective effect via significant reduction in oxidative stress-induced myocardial injury and apoptosis.
\end{abstract}

Keywords: Dexmedetomidine, Myocardial ischemia-reperfusion injury, Antioxidant status, Programmed cell death

\begin{abstract}
This is an Open Access article that uses a fund-ing model which does not charge readers or their institutions for access and distributed under the terms of the Creative Commons Attribution License (http://creativecommons.org/licenses/by/4.0) and the Budapest Open Access Initiative (http://www.budapestopenaccessinitiative.org/read), which permit unrestricted use, distribution, and reproduction in any medium, provided the original work is properly credited.

Tropical Journal of Pharmaceutical Research is indexed by Science Citation Index (SciSearch), Scopus, International Pharmaceutical Abstract, Chemical Abstracts, Embase, Index Copernicus, EBSCO, African Index Medicus, JournalSeek, Journal Citation Reports/Science Edition, Directory of Open Access Journals (DOAJ), African Journal Online, Bioline International, Open-J-Gate and Pharmacy Abstracts
\end{abstract}

\section{INTRODUCTION}

Coronary atherosclerotic heart disease constitutes a serious threat to human life and health. Due to improved economy and changes in peoples' lifestyle, the incidence of coronary heart disease has continued to increase [1]. At present, thrombolytic therapy and percutaneous coronary intervention are important methods for the treatment of coronary heart disease. 
However, myocardial ischemia-reperfusion injury (MI/RI) has become a serious problem in clinical cardiology [2]. It is known that $M I / R I$ is serious pathophysiological change in myocardial tissue caused by the restoration of blood supply, which results in severe myocardial injury, irreversible damage, and even myocardial death [3].

When MI/RI occurs, myocardial cells are damaged to different degrees, cellular structure is destroyed, and cell apoptosis is accelerated [4]. Therefore, it is important to evolve ways of effectively reducing $\mathrm{MI} / \mathrm{RI}$ so as to reduce the incidence of ischemic heart diseases and complications. Ischemic post-treatment refers to the phenomenon of myocardial protection through transient and intermittent ischemiareperfusion treatment after ischemia for a period of time, and before the beginning of reperfusion [5]. Dexmedetomidine is a new type of $\alpha 2$ receptor agonist. It has been found that dexmedetomidine pre-treatment exerts protective effects on myocardium, but very little is known about the effect of dexmedetomidine pretreatment on the myocardium [6]. This study was aimed at investigating the influence of dexmedetomidine on oxidative stress and apoptosis induced by $\mathrm{MI} / \mathrm{RI}$ in rats.

\section{EXPERIMENTAL}

\section{Animals}

Ninety (90) healthy male Wistar rats were obtained from Shanghai Ruitaimosi Biotechnology Co. Ltd, with production license SCXK (Shanghai) 2016-0001. The mean weight of the rats was $211 \pm 39 \mathrm{~g}$.

Approval for this study was obtained from the Animal Ethical Committee of First Affiliated Hospital of Jiamusi University, 348 Dexiang Street, Jiamusi City, Heilongjiang Province, China (approval no. 201831997), and the research was done in line with Principles of Laboratory Animal Care [7].

\section{Main equipment and reagents}

The main instruments and reagents used, and their sources (in brackets) were: low temperature refrigerator (Shanghai Precision instrument Co. Ltd., Model: DW-40L158); low temperature and high speed centrifuge (Shanghai Precision instrument Co. Ltd., model: GL-2050MS); Animal respirator (Shanghai Yuyan Scientific Instruments Co. Ltd., Model: SAR-1000); paraffin slicer (Hubei Xiaogan Kuohai Medical Technology Co. Ltd., model: KH-Q350); optical microscope (Shanghai Optical instrument
Factory, Model: SG-51); SOD assay kit (Nanjing Senbeijia Biotechnology Co. Ltd., specification: 100T), and MDA assay kit (Beijing Baiaolaibo Technology Co. Ltd., specification: 100T). The others were GSH-Px assay kit (Shanghai Suobao Biotechnology Co. Ltd., specification: 50T); LDH assay kit (DOJINDO Laboratories, specification: 100T); CK-MB assay kit (Shanghai Yiyan Biotechnology Co. Ltd., specification: 96T); TUNEL apoptosis analysis kit (Beijing Baiaolaibo Technology Co. Ltd., specification: 50T), and dexmedetomidine (Jiangsu Hengrui Pharmaceutical Co. Ltd., production batch number: 20170248, specification: $2 \mathrm{~mL}: 200 \mathrm{~g}$ ).

\section{Animal grouping}

The 90 rats were assigned to three groups (30/group) using the digital random table method: sham operation, model and dexmedetomidine post-treatment groups. In the model group, the anterior descending branch of the left coronary artery was ligated for $25 \mathrm{~min}$, and the rats were subjected to reperfusion for $2 \mathrm{~h}$. Rats in the posttreatment group were similarly ligated in the anterior descending branch of the left coronary artery for 25 min, but were intravenously injected with dexmedetomidine at a dose of $10 \mu \mathrm{g} / \mathrm{kg}$ prior to reperfusion. There was no ligation in the sham operation group.

\section{Treatment indices}

\section{Parameters of redox status}

Malondialdehyde (MDA) in each group was determined using TBARS procedure. Glutathione peroxidase (GSH-Px) and SOD were assayed colorimetrically. The activities LDH and CK-MB were assayed using automatic biochemical analyzer. Pathological changes in cardiomyocytes in each group were determined histologically using $\mathrm{H}$ \& $\mathrm{E}$ staining.

\section{Apoptosis}

Apoptosis in rats in each group was measured using TUNEL assay.

\section{Statistical analysis}

All statistical analyses were done with SPSS software package version 22.0. Single factor variance analysis and LSD-t test were used for comparing measurement data. Count data were compared with $X^{2}$ test, while Ridit test was used to compare grade data. Values of $p<0.05$ were taken as indicative of statistical significance difference. 


\section{RESULTS}

\section{Oxidative stress}

Table 1 shows that model rat MDA concentration was markedly increased, while superoxide dismutase and glutathione reductase activities were markedly reduced, relative to sham operation rats $(p<0.05)$. However, this trend was reversed in the post-treatment group, relative to model rats $(p<0.05)$.

Table 1: Oxidative stress indices (mean $\pm S D, n=30$ )

\begin{tabular}{lccc}
\hline Group & $\begin{array}{c}\text { GSH-Px } \\
(\mathbf{U} / \mathrm{mL})\end{array}$ & $\begin{array}{c}\text { SOD } \\
(\mathbf{p g} / \mathbf{m L})\end{array}$ & MDA (U/L) \\
\hline Sham & $22.62 \pm$ & $69.16 \pm$ & $574.54 \pm$ \\
& 2.29 & 2.53 & 49.36 \\
Model & $13.91 \pm$ & $43.28 \pm$ & $798.34 \pm$ \\
Post- & $1.13^{\mathrm{a}}$ & $2.98^{\mathrm{a}}$ & $67.11^{\mathrm{a}}$ \\
treatment & $15.78 \pm$ & $55.49 \pm$ & $677.63 \pm$ \\
$F$ & $1.48^{\mathrm{ab}}$ & $1.43^{\mathrm{ab}}$ & $61.09 \mathrm{ab}$ \\
$P$-value & 217.211 & 870.703 & 105.814 \\
\hline${ }^{a} P<0.05$, vs sham rats; ${ }^{b} p<0.05$, vs model rats
\end{tabular}

\section{LDH and CK-MB activities}

The activities of LDH and CK-MB were markedly higher in model rats than in sham rats, but they were markedly decreased in the post-treatment group than in the model rats $(p<0.05$; Table 2$)$.

Table 2: $\mathrm{LDH}$ and CK-MB levels (mean $\pm \mathrm{SD}, \mathrm{n}=3$ )

\begin{tabular}{lcc}
\hline Group & LDH (KU/L) & CK-MB (U/mL) \\
\hline Sham & $0.11 \pm 0.02$ & $15.22 \pm 2.11$ \\
Model & $1.33 \pm 0.14^{\mathrm{a}}$ & $107.19 \pm 7.78^{\mathrm{a}}$ \\
Post-treatment & $0.76 \pm 0.06^{\mathrm{ab}}$ & $85.82 \pm 8.06^{\mathrm{ab}}$ \\
$F$ & 1421.063 & 1604.481 \\
$P$-value & $<0.001$ & $<0.001$ \\
${ }^{a} P<0.05$, vs sham rats; ${ }^{b} p<0.05$, vs model rats
\end{tabular}

\section{Pathological changes in myocardial cells}

As shown in Figures $1 \mathrm{~A}-1 \mathrm{C}$, cardiomyocytes in sham rat were in orderly arrangement, with intact cell membranes, and there was no inflammatory infiltration. In the model group, the arrangement of cardiomyocytes was disordered, with widened spaces between muscle fibers, and high level of red blood cell exosmosis. Moreover, there was high level of inflammatory cell infiltration. In contrast, cardiomyocyte damage was less in post-treatment rats than in model rats.

\section{Apoptosis}

Apoptosis in model rats was markedly higher than in sham operation rats, but was significantly lower in post-treatment rats than in model rats $(p$ $<0.05$; Figure 2 and Table 3).
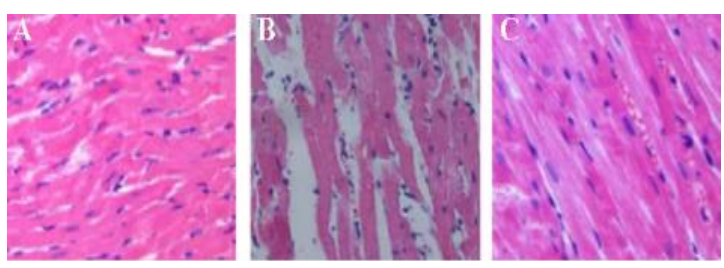

Figure 1: Pathological changes in cardiomyocytes of rats in the three groups. A: Sham group; B: Model group; C: Post-treatment group
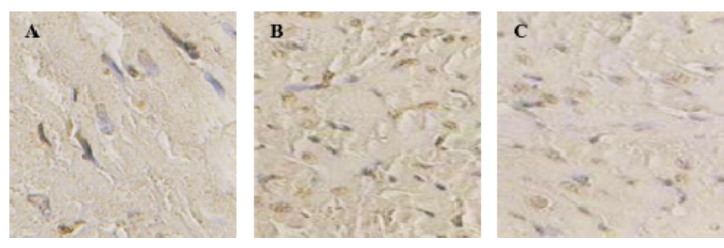

Figure 2: Effect of treatments on apoptosis in the three groups of rats. A: Sham operation group; B: model group; C: post-treatment group.

Table 3: Apoptosis among the rats (mean \pm SD, $n$ $=30$ )

\begin{tabular}{lc}
\hline Group & $\begin{array}{c}\text { Apoptosis } \\
\text { (quantity) }\end{array}$ \\
\hline Sham & $0.71 \pm 0.06$ \\
Model & $38.54 \pm 2.06^{\mathrm{a}}$ \\
Post-treatment & $26.38 \pm 2.06 \mathrm{ab}$ \\
$F$ & 3953.564 \\
$P$-value & $<0.001$ \\
\hline${ }^{a} P<0.05$, vs sham rats; ${ }^{b} p<0.05$, vs model rats
\end{tabular}

\section{DISCUSSION}

Myocardial ischemia-reperfusion injury (MI/RI) is one of the most common problems encountered in clinical cardiac surgery. The mechanism involved is complex, and it is thought to be closely related to oxidative stress, inflammatory reaction, autophagy and apoptosis [8]. At present, many types of drugs such as sodium and hydrogen exchange inhibitors and calcium antagonists are used in clinical management of $\mathrm{MI} / \mathrm{RI}$. Dexmedetomidine is a new type of $\alpha 2$ receptor agonist which has sedative, analgesic, anti-anxiety, oxidative stress-reducing, and inflammatory response-lowering effects in the central nervous system. In addition, dexmedetomidine inhibits sympathetic nerve activity, relaxes blood vessels, and reduces blood pressure [9]. In this study, the effect of dexmedetomidine post-treatment on oxidative stress and apoptosis induced by $\mathrm{MI} / \mathrm{RI}$ was studied.

Oxidative stress is a disequilibrium in redox status, and it is associated with free radical generation in the body [10]. Under normal 
physiological conditions, the oxidation and antioxidant reactions are in a state of balance, resulting in a dynamic balance between ROS generation and their clearance. This is beneficial and harmless to the body. However, when MI/RI occurs, this homeostasis is broken, and the rate of production of oxygen free radicals is significantly higher than the rate at which they are scavenged, resulting in lipid peroxideinduced damage to the cell membrane, cell injury and apoptosis [11].

The enzyme, GSH-Px, protects the structure and function of the cell membrane from damage by lipid peroxides. In addition, SOD is an important antioxidant enzyme which plays a key role in the neutralization of oxygen free radicals. Malondialdehyde (MDA) is the final product of lipid oxidation which increases membrane damage. It is an important index for indirect assessment of the extent of lipid peroxidation and membrane damage [12]. In the present study, model rat MDA was significantly increased, while the activities of SOD and GSHPx were markedly decreased, when compared with the sham operation group. The pattern of changes in MDA and antioxidant enzymes indicate that $\mathrm{MI} / \mathrm{RI}$-induced redox imbalance can be significantly alleviated by post-treatment with dexmedetomidine.

Under normal conditions, LDH, a cytoplasmic enzyme, is present in high levels in myocardial tissue. However, when myocardial ischemia occurs, the release of inflammatory mediators is increased; large numbers of free radicals are generated, the permeability of the cell membrane is increased, and serum LDH level is increased.

Lactate dehydrogenase ( $\mathrm{LDH})$ is a sensitive index of cardiomyocyte injury [13]. Skeletal muscle and myocardium are rich in CK-MB, which is the most sensitive index of myocardial tissue damage [14]. In the sham rats, the cardiomyocytes were arranged neatly, the cell membrane was intact, and there was no inflammatory infiltration.

However, in model rats, there was disorderly arrangement of cardiomyocytes, with wide spaces between muscle fibers, and pronounced red blood cell exosmosis, Moreover, there was a high degree of inflammatory cell infiltration. There was less cardiomyocyte damage in posttreatment rats than in model rats. These results suggest that the post-treatment with dexmedetomidine maintained the cellar morphology and structure of normal myocardial, and reduced myocardial injury.
Apoptosis is one of the mechanisms involved in MI/RI. Studies have found that almost all cases of acute myocardial infarction are associated with presence of typical apoptotic cells in the myocardium [15].

Studies by Han et al [16] reported that inhibition of cardiomyocyte apoptosis significantly reduced $\mathrm{MI} / \mathrm{RI}$ in patients, and that apoptosis was associated with the severity of MI/RI. It was found that apoptosis was significantly higher in model rats than in sham operation rats, while apoptosis was lower in post-treatment rats than in model rats. These results suggest that posttreatment with dexmedetomidine exerts inhibitory effect on cardiomyocyte apoptosis in rats.

\section{Limitations of the study}

There were no differences in concentrations of dexmedetomidine in this study. Thus, the effect of different concentrations of dexmedetomidine on oxidative stress and apoptosis after myocardial ischemia-reperfusion injury in rats is not yet clear.

\section{CONCLUSION}

Post-treatment with dexmedetomidine significantly reduces apoptosis and myocardial injury caused by oxidative stress. Thus, dexmedetomidine exerts protective effects on the myocardium. This provides a basis for the development of other drugs.

\section{DECLARATIONS}

\section{Acknowledgement}

This study was supported by Scientific Research Project of Heilongjiang Health and Family Planning Commission (no. 2018-314).

\section{Conflict of interest}

No conflict of interest is associated with this work.

\section{Contribution of authors}

We declare that this work was done by the author(s) named in this article and all liabilities pertaining to claims relating to the content of this article will be borne by the authors. All authors read and approved the manuscript for publication. Xianfeng Xin conceived and designed the study. Zhihai Geng, Xuelian Zhu, Xi Han, Xianfeng Xin collected and analysed the data, while Zhihai Geng wrote the manuscript. 


\section{Open Access}

This is an Open Access article that uses a funding model which does not charge readers or their institutions for access and distributed under the terms of the Creative Commons Attribution License (http://creativecommons.org/licenses/by/ 4.0) and the Budapest Open Access Initiative (http://www.budapestopenaccessinitiative.org/rea d), which permit unrestricted use, distribution, and reproduction in any medium, provided the original work is properly credited.

\section{REFERENCES}

1. Wong MC, Zhang DX, Wang HH. Rapid emergence of atherosclerosis in Asia: a systematic review of coronary atherosclerotic heart disease epidemiology and implications for prevention and control strategies. Curr Opin Lipidol 2015; 26(4): 257.

2. Zhou H, Ma Q, Zhu P, Ren J, Reiter RJ, Chen Y. Protective role of melatonin in cardiac ischemiareperfusion injury: From pathogenesis to targeted therapy. J Pineal Res 2018; 64(3): 12471.

3. Liu Y, Zou J, Liu X, Zhang Q. MicroRNA-138 attenuates myocardial ischemia reperfusion injury through inhibiting mitochondria-mediated apoptosis by targeting HIF1- $\alpha$. Exp Ther Med 2019; 18(5): 3325-3332.

4. Wu $\mathrm{H}$, Ye M, Yang J, Ding J. Endoplasmic reticulum stress-induced apoptosis: A possible role in myocardial ischemia-reperfusion injury. Int J Cardiol 2016; 208(2): 65-66.

5. Cheng $X Y, G u X Y$, Gao Q, Zong QF, Li XH, Zhang $Y$. Effects of dexmedetomidine postconditioning on myocardial ischemia and the role of the PI3KJAktdependent signaling pathway in reperfusion injury. Mol Med Rep 2016; 14(1): 797-803.

6. Ren J, Li C, Liu Y, Dong Z. Protective effect of dexmedetomidine against myocardial ischemiareperfusion injury in rabbits. Acta Cir Bras 2018; 33(1): 22-30.

7. World Health Organization. Principles of laboratory animal care. WHO Chron 1985; 39: 51-56.

8. Hu T, Wei G, Xi M, Yan J, Wu X, Wang Y, Zhu Y, Wang $C$, Wen A. Synergistic cardioprotective effects of
Danshensu and hydroxysafflor yellow $A$ against myocardial ischemia-reperfusion injury are mediated through the Akt/Nrf2/HO-1 pathway. Int J Mol Med 2016; 38: 83-94.

9. Cheng $X, H u$ J, Wang $Y$, Ye H, Li X, Gao Q, Li Z. Effects of Dexmedetomidine Postconditioning on Myocardial Ischemia/Reperfusion Injury in Diabetic Rats: Role of the PI3K/Akt-Dependent Signaling Pathway. J Diabetes Res 2018; 2018: 3071959.

10. Yu $H$, Guan $Q$, Guo L, Zhang $H$, Pang $X$, Cheng $Y$, Zhang $X$, Sun $Y$. Gypenosides alleviate myocardial ischemia-reperfusion injury via attenuation of oxidative stress and preservation of mitochondrial function in rat heart. Cell Stress Chaperones 2016; 21(3): 429-437.

11. Yu L, Li S, Tang X, Li Z, Zhang J, Xue X, Han J, Liu Y, Zhang $Y$, Zhang $Y$, et al. Diallyl trisulfide ameliorates myocardial ischemia-reperfusion injury by reducing oxidative stress and endoplasmic reticulum stressmediated apoptosis in type 1 diabetic rats: role of SIRT1 activation. Apoptosis 2017; 22(7): 942-954.

12. Cai Z, Shi $T$, Zhuang $R$, Fang $H$, Jiang $X$, Shao $Y$, Zhou $H$. Protective effect of $\mathrm{N}$-acetylcysteine activated carbon release microcapsule on myocardial ischemiareperfusion injury in rats. Exp Ther Med 2018; 15(2): 1809-1818.

13. Zhang WP, Zong $Q F$, Gao Q, Yu Y, Gu XY, Wang $Y, L i$ $\mathrm{ZH}, \mathrm{Ge} M$. Effects of endomorphin-1 postconditioning on myocardial ischemia/reperfusion injury and myocardial cell apoptosis in a rat model. Mol Med Rep 2016; 14(4): 3992-3998.

14. Liu ZY, Hu S, Zhong QW, Tian CN, Ma HM, Yu JJ. NMethyl-d-Aspartate Receptor-Driven Calcium Influx Potentiates the Adverse Effects of Myocardial IschemiaReperfusion Injury Ex Vivo. J Cardiovasc Pharmacol 2017; 70(5): 329-338.

15. Yan J, Duan J, Wu X, Guo C, Yin Y, Zhu Y, Hu T, Wei G, Wen A, Xi M. Total saponins from Aralia taibaiensis protect against myocardial ischemia/reperfusion injury through AMPK pathway. Int J Mol Med 2015; 36(6): 1538-1546.

16. Han J, Xuan JL, Hu HR, Chen ZW. Protective effect against myocardial ischemia reperfusion injuries induced by hyperoside preconditioning and its relationship with PI3K/Akt signaling pathway in rats. Zhongguo Zhong Yao Za Zhi 2015; 40(1): 118-123. 